\title{
Nectar Secretion Rhythms and Nectar Energetics of Trifolium alexandrinum Flowers
}

\author{
M.K. Jat*, O.P. Chaudhary and A.S. Tetarwal \\ Department of Entomology, College of Agriculture, CCS, Haryana Agricultural University \\ Hisar, 125 004, Haryana, India \\ *Corresponding author
}

\begin{abstract}
A B S T R A C T
Keywords

DNS, Nectar, energy, Egyptian clover

Article Info

Accepted:

07 November 2018

Available Online:

10 December 2018

The investigations on Nectar secretion rhythms and nectar energetics of Trifolium alexandrinum flowers were carried at Forage Section, Department of Genetics and Plant Breeding, CCS, Haryana Agricultural University, Hisar during 2012 and 2013. A T. alexandrinum flower produced a mean dry nectar sugars (DNS) of $1.95 \mathrm{mg}$ and its amount in 2013 was higher (2.168 mg/flower) than 2012 (1.734 mg). Physiologically mature flower (fully opened) produced maximum amount of DNS $(2.453 \mathrm{mg})$ followed by half (1.900) and just opened flowers $(1.500 \mathrm{mg})$. The maximum DNS $(2.027 \mathrm{mg})$ was produced at $1300 \mathrm{~h}$ followed by at 1000 and $1600 \mathrm{~h}(1.926$ and $1.900 \mathrm{mg}$, respectively) which were at par with each other. The fully opened flowers produced maximum DNS at all the observed time intervals of 1000,1300 and $1600 \mathrm{~h}(2.468,2.446$ and $2.444 \mathrm{mg} /$ flower, respectively) followed by half opened flowers in the afternoon hours of 1300 and $1600 \mathrm{~h}$ (1.947 and $1.921 \mathrm{mg}$, respectively) while it was lower in the morning hours at $1.832 \mathrm{mg}$.
\end{abstract}

\section{Introduction}

Egyptian clover, Trifolium alexandrinum L popularly called berseem (Family Leguminaceae, sub-family Papilionaceae). Egyptian clover is one of the most entomophilic crop requiring insects, especially bees for cross pollination. The quantity and quality of the floral rewards (nectar and/or pollen) presented by the plants governs the diversity and amount of floral visitors. $T$. alexandrinum produces glucose-dominated nectar whose average sugar concentration varies from 29 to 66 per cent. The nectar is secreted at the base of the stamens and collected in the corolla tube. Braun et al., (1953) reported that due to evaporation, sugar concentration increases during the day to about 50-60 per cent thus, changing the nectar concentration and volume eventually, the foraging behavior. Honeybees thus, forage $T$. alexandrinum for nectar in the morning and pollen in the afternoon. Abrol and Kapil (1991) determined that $T$. alexandrinum nectar was glucose dominated and was preferred by A. florea and P. smaragdula while A. dorsata, M. cephalotes, M. lanata and $X$. fenestrata visited flowers with sucrose-dominated nectar more frequently. According to Narayanan et al., (1961) the sun rose about 5.30 to $5.40 \mathrm{~h}$ 
during April- May, which was the period when berseem flowered, the bee visit did not start till $0700 \mathrm{~h}$ and the maximum bee visits was recorded from 0800 to $1100 \mathrm{~h}$. It shows that nectar secretion was associated with light and temperature and that sufficient nectar of the desired consistency was not available till two hours after the sunrise, indicating hot and dry condition as conducive to good nectar secretion. A. indica was the major pollinatorwhen nectar secretion was poor.

\section{Materials and Methods}

Nectar secretion rhythms and nectar energetics of $T$. alexandrinum flowers

The nectar secretion rhythms of $T$. alexandrinum cultivar "HB-2" flowers, estimated as the amount of dry nectar sugars produced during different period of the day $(1000,1300$ and $1600 \mathrm{~h})$ in three different physiological floral stages viz., just opened, half opened and fully opened flowers were determined.

\section{Nectar secretion rhythm of $T$. alexandrinum flowers}

For quantitative estimation of dry nectar sugars (DNS) in T. alexandrinum flowers, method of Roberts (1979) was followed. Justopened, half-opened and fully-opened flowers were collected from already marked plants in each replication consisting of 10 flowers.

Flower samples were collected in capped plastic vials $(15 \mathrm{ml})$ and washed for 45-60 minutes with $5 \mathrm{ml}$ of distilled water with frequent shaking so as to rinse the nectarines. Nectar washed flowers were then taken out from the tubes and the rinsates were stored in sealed plastic vials in a freezer (to avoid contamination by fungus) for further analysis. Contamination of the sample with sugar in the form of cellulose from lint or plant tissue was avoided. The freezedrinsate was thawed first and aliquots of $0.1,0.3,0.5,0.7$ and $1 \mathrm{ml}$ were taken, and final volume was made to $1 \mathrm{ml}$ by adding distilled water. These aliquots were further processed so as to get the optical density (OD) in the range of 0.1 to 0.9 , considered best for accurate measurement. Blank or control test tube consisted of one $\mathrm{ml}$ of distilled water only. To each tube, $1 \mathrm{ml}$ of 5 per cent phenol solution was added followed by $5 \mathrm{ml}$ of concentrated $\mathrm{H}_{2} \mathrm{SO}_{4}$. The final hot solution was mixed thoroughly with the help of test tube shaker and allowed to rest for 45 minutes for color development. After 45 minutes, absorbance of the solution was measured with double beam Spectrophotometer 2203 at $490 \mathrm{~nm}$ (Jenway). The amount of sugar corresponding to the observed absorbance (OD) was then estimated from the standard glucose curve to obtain the total amount of dry sugars per flower (expressed as glucose equivalent).

\section{Standard curve:}

For preparing standard curve, $10 \mathrm{mg}$ glucose (GR, Merck) was dissolved in $100 \mathrm{ml}$ of distilled water. From this stock solution, aliquots of $0.1,0.2,0.3,0.4,0.5,0.6,0.7,0.8$, 0.9 and $1.0 \mathrm{ml}$ were taken in separate test tubes. Final volume of each aliquot was made to $1.0 \mathrm{ml}$ by adding required amount of distilled water. Distilled water was taken as control or blank. Glucose values were estimated as already discussed above. Glucose values of nectar sugars in unknown samples were thus, determined by using this standard curve and represented as glucose equivalent sugar. The weather data during the period of investigation was also recorded. The data was subjected to analysis of variance.

\section{Energy production rhythms in $T$. alexandrinum flowers}

The amount of energy produced by an $T$. alexandrinum flower through its nectar was calculated following the method of Heinrich 
(1975), based on the principle that $1 \mathrm{mg}$ of sugar (irrespective of its type) yields 4 calorie of energy that is equivalent to 16.74 joules of energy $\left\{\right.$ i.e., Energy flower ${ }^{-1}$ day $^{-1}=$ amount of sugar x 16.74 (joules)\}. The energy produced by each flowers of three different physiological stages (just, half and fully opened) during different period of the day $(1000,1300$ and $1600 \mathrm{~h})$ was calculated and the data was subjected to statistically analysis of variances.

\section{Results and Discussion}

\section{Nectar secretion rhythm of $T$. alexandrinum} flowers

The amount, concentration and rhythms of nectar sugars (DNS) and consequently the energetic of nectar production determines host flowers suitability and selection by the floral visitors which in turn govern their abundance, spatial distribution and finally host pollination. Nectar sugars determined as dry nectar sugar are foraged to fulfill energy needs of the individuals and colony. Rhythms of DNS production in $T$. alexandrinum flowers of three different physiological stages (justopened, half-opened and fully-opened florets) at three different time intervals (1000, 1300 and $1600 \mathrm{~h}$ ) were determined during these studies (Table 1, 2 and Fig. 1).

In the present studies, a flower of $T$. alexandrinum during its entire life cycle was found to produce $1.951 \mathrm{mg}$ DNS. These findings are partially supported by Jablonski (1974) who also recorded a range of 1.8-3.53 mg/flower with sugar concentration of 57.365.4 per cent while Maurizio and Pinter (1961) on the other hand observed that a singleflower produced about $0.22 \mathrm{mg}$ of nectar per day with a mean sugar concentration of 30 per cent. McGregor and Todd (1952) reported nectar amount to vary from very small to copious and calculated that in one acre, about 1.7 pounds of nectar is produced each day.
During 2013, a higher amount of DNS (2.168 mg/flower) was recorded compared to 1.734 $\mathrm{mg}$ during 2012. Flowers when they were fully opened produced maximum DNS (2.453 mg/flower) while just opened ones produced minimum amount $(1.500 \mathrm{mg})$ and the half opened flowers produced intermediate amounts $(1.900 \mathrm{mg})$. DNS production in just open flowers was almost similar in both the years but in half and fully opened flowers, higher amounts were found during 2013 (2.096 and $2.960 \mathrm{mg}$ ) than 2012 (1.704 and $1.904 \mathrm{mg}$, respectively). No work on $T$. alexandrinum has been reported in literature and this study forms the first report on nectar secretion rhythms. However, these findings find support from Chaudhary (2007) on peach and Nagar and Chaudhary (2005)on strawberry who reported that the determination of DNS levels at a particular time interval in fact, is the sum of flower's innate production capacity at a particular physiological stage (age) and the nectar loss through evaporation (due to weather factors) and the nectar withdrawn by the floral visitors. Presence of similar amount of DNS in just open flowers during both the years clearly indicated a similar innate potential of flower. But the higher amounts in half and fully opened flowers during 2013 than 2012 may be explained through nectar's higher losses through evaporation and insect withdrawal, which is further corroborated explained from the higher mean abundance of insect visitors during 2012 (19.61) than 2013 (17.94). Braun et al., (1953) also made similar observations that due to evaporation, sugar concentration increases during the day to about 50-60 per cent that changes nectar concentration and volume.

Diurnal variations in DNS production were observed in these studies. The $T$. alexandrinum flowers produced maximum DNS (2.027 mg) at $1300 \mathrm{~h}$ and lower but statistically similar amounts at 1000 and 1600 h (1.926 and $1.900 \mathrm{mg})$. 
Table.1 Nectar secretion rhythms in T. alexandrinum flowers during different years

\begin{tabular}{|c|c|c|c|c|c|c|c|c|}
\hline \multirow[t]{3}{*}{ Stage of flowers } & \multicolumn{8}{|c|}{ Dry nectar sugar produced (mg/flower) during different periods of the day (h) } \\
\hline & \multicolumn{4}{|c|}{2012} & \multicolumn{4}{|c|}{2013} \\
\hline & 1000 & 1300 & 1600 & Mean & 1000 & 1300 & 1600 & Mean \\
\hline Just Opened & $1.567 *$ & 1.591 & 1.498 & 1.552 & 1.391 & 1.783 & 1.171 & 1.448 \\
\hline Half Opened & 1.792 & 1.683 & 1.636 & 1.704 & 1.872 & 2.211 & 2.205 & 2.096 \\
\hline Full Opened & 1.945 & 1.998 & 1.892 & 1.945 & 2.991 & 2.893 & 2.995 & 2.960 \\
\hline $\mathrm{CD}(\mathrm{p} \leq 0.05)$ & & N.S. & & 0.110 & & 0.247 & & 0.143 \\
\hline SE(m) & & 0.063 & & 0.036 & & 0.082 & & 0.047 \\
\hline Mean & 1.757 & 1.768 & 1.675 & 1.734 & 2.085 & 2.296 & 2.124 & 2.168 \\
\hline $\mathrm{CD}(\mathrm{p} \leq 0.05)$ & & N.S. & & & & 0.143 & & \\
\hline $\mathrm{SE}(\mathrm{m})$ & & 0.036 & & & & 0.047 & & \\
\hline
\end{tabular}

*Values are the mean of 10 flowers and 3 replications each

Table.2 Mean nectar secretion rhythms in different stages of T. alexandrinum flowers during different periods of the day

\begin{tabular}{|c|c|c|c|c|c|c|c|}
\hline \multirow{2}{*}{$\begin{array}{l}\text { Stage of } \\
\text { flowers }\end{array}$} & \multicolumn{7}{|c|}{ Dry nectar sugar produced (mg/flower) during different periods of day (h) } \\
\hline & 2012 & 2013 & Mean & 1000 & 1300 & 1600 & Mean \\
\hline Just Opened & 1.552 & 1.448 & 1.500 & 1.479 & 1.687 & 1.335 & 1.500 \\
\hline Half Opened & 1.704 & 2.096 & 1.900 & 1.832 & 1.947 & 1.921 & 1.900 \\
\hline Full Opened & 1.945 & 2.960 & 2.453 & 2.468 & 2.446 & 2.444 & 2.453 \\
\hline $\mathrm{CD}(\mathrm{p} \leq 0.05)$ & \multicolumn{2}{|c|}{0.117} & 0.083 & & 0.029 & & 0.083 \\
\hline $\mathrm{SE}(\mathbf{m})$ & \multicolumn{2}{|c|}{0.041} & 0.029 & & 0.05 & & 0.029 \\
\hline Mean & 1.734 & 2.168 & 1.951 & 1.926 & 2.027 & 1.900 & 1.951 \\
\hline $\mathrm{CD}(\mathrm{p} \leq 0.05)$ & \multicolumn{2}{|c|}{0.068} & & & 0.083 & & \\
\hline SE(m) & \multicolumn{2}{|c|}{0.024} & & & 0.029 & & \\
\hline
\end{tabular}

Table.3 Energy production rhythms in T. alexandrinum flowers during different years

\begin{tabular}{|c|c|c|c|c|c|c|c|c|}
\hline \multirow[t]{3}{*}{ Stage of flowers } & \multicolumn{8}{|c|}{ Energy production (joules/flower) during different periods of day (h) } \\
\hline & \multicolumn{4}{|c|}{2012} & \multicolumn{4}{|c|}{2013} \\
\hline & 1000 & 1300 & 1600 & Mean & 1000 & 1300 & 1600 & Mean \\
\hline Just Open & 26.23 & 26.63 & 25.08 & 25.98 & 23.29 & 29.85 & 19.60 & 24.25 \\
\hline Half Open & 30.00 & 28.17 & 27.39 & 28.52 & 31.34 & 37.01 & 36.91 & 35.09 \\
\hline Full Open & 32.56 & 33.45 & 31.67 & 32.56 & 50.07 & 48.43 & 50.14 & 49.54 \\
\hline $\mathrm{CD}(\mathrm{p} \leq 0.05)$ & & N.S. & & 1.84 & & 4.14 & & 2.39 \\
\hline $\mathrm{SE}(\mathrm{m})$ & & 1.06 & & 0.61 & & 1.37 & & 0.79 \\
\hline Mean & 29.60 & 29.42 & 28.05 & 36.29 & 34.90 & 38.43 & 35.55 & 29.02 \\
\hline $\mathrm{CD}(\mathrm{p} \leq 0.05)$ & & N.S. & & & & 2.39 & & \\
\hline $\mathrm{SE}(\mathrm{m})$ & & 0.61 & & & & 0.79 & & \\
\hline
\end{tabular}

$*$ Values are the mean of 10 flowers and 3 replications each 
Table.4 Mean energy production rhythms in different stages of T. alexandrinum flowers during different periods of the day

\begin{tabular}{|c|c|c|c|c|c|c|c|}
\hline \multirow[t]{2}{*}{$\begin{array}{l}\text { Stage of } \\
\text { flowers }\end{array}$} & \multirow[b]{2}{*}{2012} & \multicolumn{6}{|c|}{$\begin{array}{l}\text { Energy production (joules/flower) during different periods of day } \\
\text { (h) }\end{array}$} \\
\hline & & 2013 & Mean & 1000 & 1300 & 1600 & Mean \\
\hline Just Open & 25.98 & 24.25 & 25.11 & 24.76 & 28.24 & 22.34 & 25.11 \\
\hline Half Open & 28.52 & 35.09 & 31.80 & 30.67 & 32.59 & 32.15 & 31.80 \\
\hline Full Open & 32.56 & 49.54 & 41.05 & 41.32 & 40.94 & 40.91 & 41.05 \\
\hline $\mathrm{CD}(\mathrm{p} \leq 0.05)$ & \multicolumn{2}{|c|}{1.13} & 1.39 & & 2.40 & & 1.39 \\
\hline SE(m) & \multicolumn{2}{|c|}{0.40} & 0.48 & & 0.84 & & 0.48 \\
\hline Mean & 29.02 & 36.29 & 29.09 & 32.25 & 33.92 & 31.80 & 29.09 \\
\hline $\mathrm{CD}(\mathrm{p} \leq 0.05)$ & \multicolumn{2}{|c|}{1.96} & & & 1.39 & & \\
\hline $\mathrm{SE}(\mathrm{m})$ & \multicolumn{2}{|c|}{0.68} & & & 0.48 & & \\
\hline
\end{tabular}

Fig.1 Nectar secretion rhythms in T. alexandrinum flowers

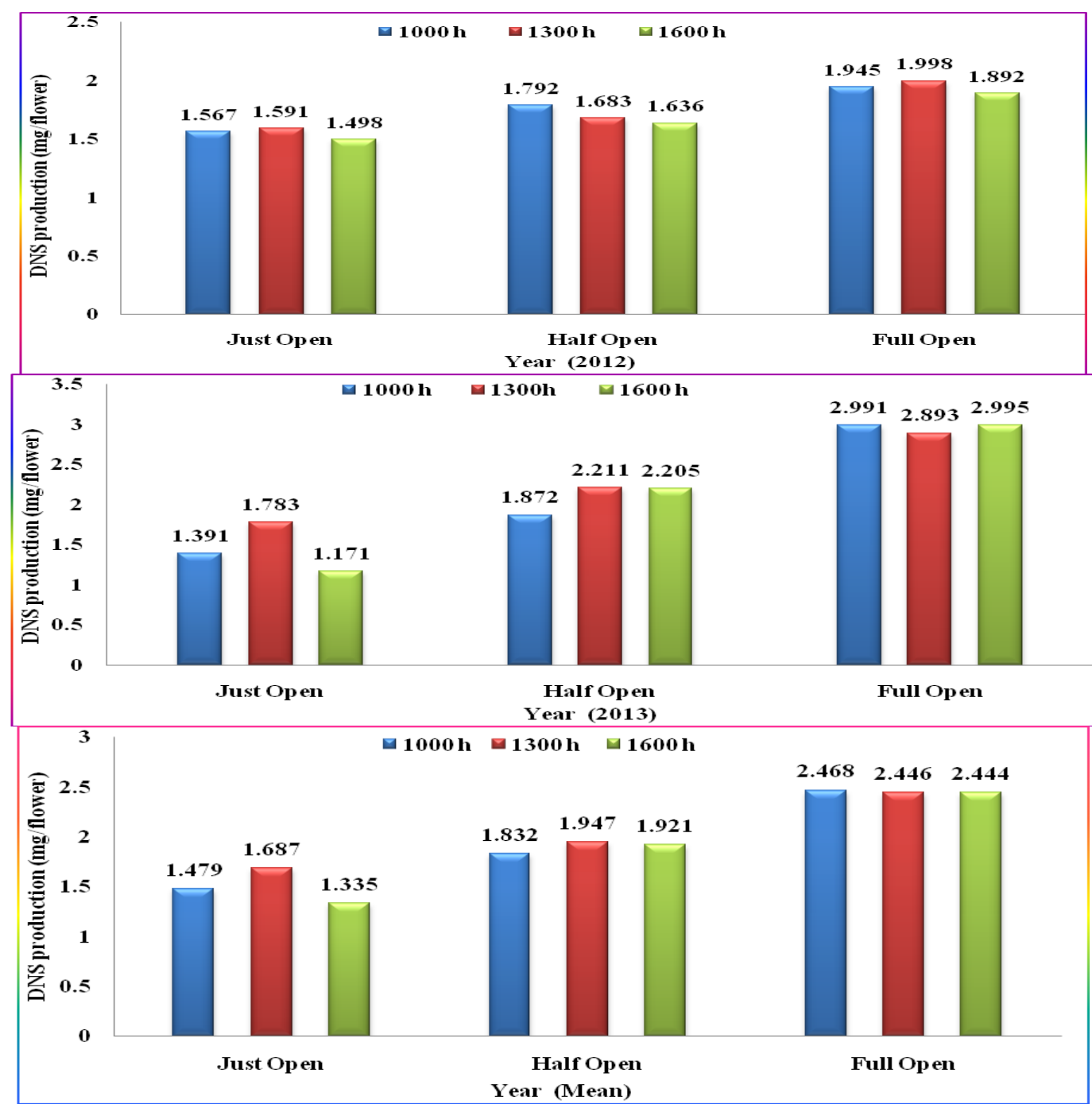


Fig.2 Energy production rhythms in T. alexandrinum flowers

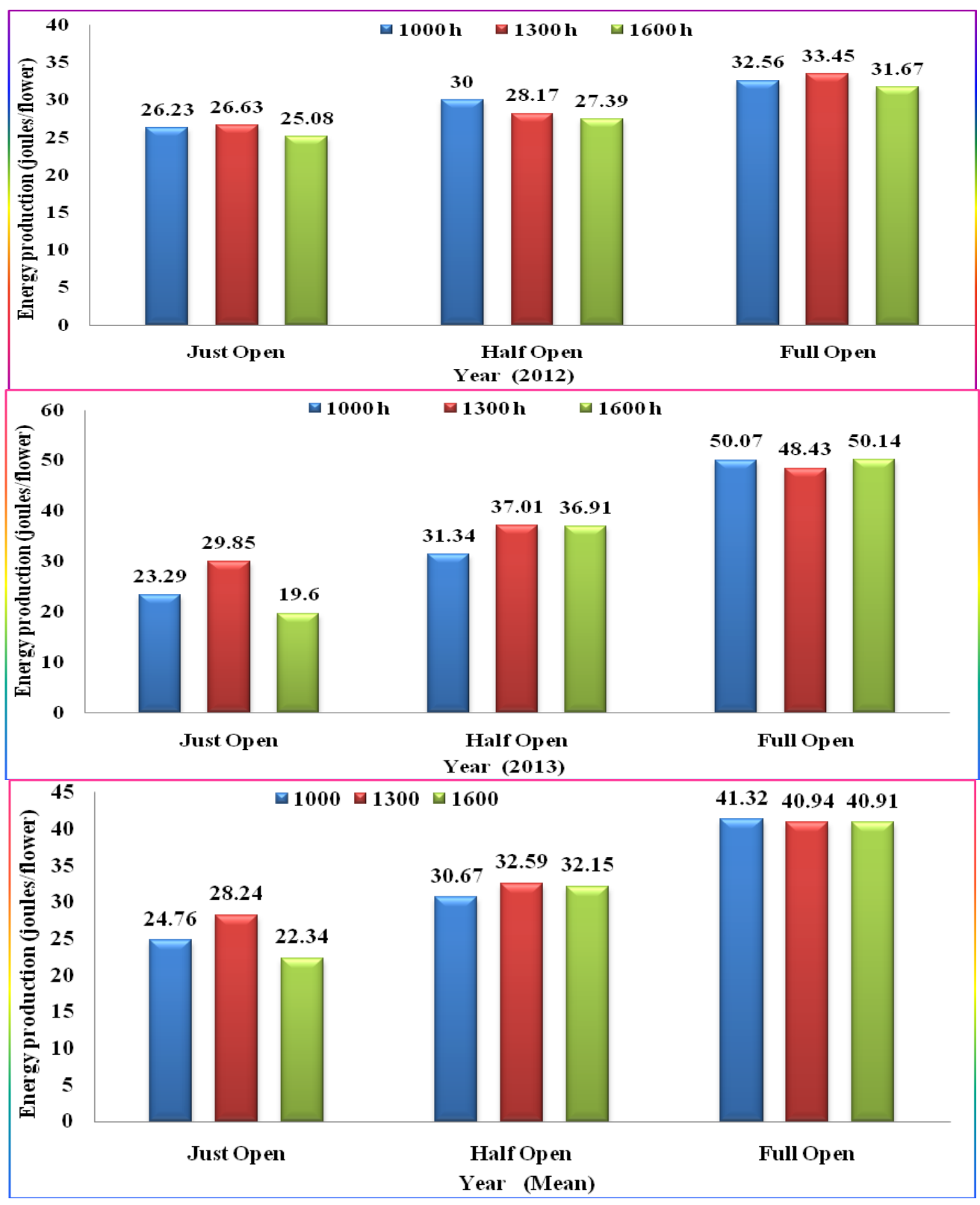

The flower in physiologically mature stage (full opened) produced maximum DNS during all the time intervals of 1000,1300 and 1600 $\mathrm{h}(2.468,2.446$ and $2.444 \mathrm{mg} /$ flower, respectively) while those in immature stage (just opened) were recorded with minimum DNS amounts at $1600 \mathrm{~h}(1.335 \mathrm{mg})$ followed by at $1000(1.479)$ and $1300 \mathrm{~h}(1.687 \mathrm{mg})$. In half opened flowers, higher DNS was recorded during the afternoon hours of 1300 and $1600 \mathrm{~h} \quad(1.947$ and $1.921 \mathrm{mg}$, respectively) while it was lower $(1.832 \mathrm{mg})$ in the morning $(1000 \mathrm{~h})$. Confirming these observations on diurnal variations of nectar, Pedersen (1953), Pedersen and Bohart (1953) Pedersen and Todd (1949) and McGregor and Todd (1952) also reported the governance of nectar concentration by genotypes, temperature, humidity and time. However, Narayanan et al., (1961) in contrast, recorded 
maximum bee visit from 0800 to $1100 \mathrm{~h}$ when sufficient nectar of desired consistency was available.

\section{Energy production rhythms in $T$. alexandrinum flowers}

The nectar rewards presented by the flower provide the flower visitors with the carbohydrates that in turn produce energy required for all of its life functions. The amount of energy provided by a flower and the crop determines the abundance of floral visitors (Table 3, 4 and Fig. 2). The energy production rhythms thus, predictably followed the DNS rhythms in the present investigations. Studies clearly revealed that $T$. alexandrinum flowers produced significantly higher amount of energy during 2013 (36.39 joules/flower) than 2012 (29.02). Physiologically mature fully opened flowers produced maximum energy (41.05 joules) followed by half opened (31.80) and the minimum by just opened flowers (25.11 joules). Nectar is the product of photosynthesis and at maximum intensity of Sun light at $1300 \mathrm{~h}$, the maximum amount of energy was produced by the flowers (33.92 joules) whereas, in the morning and evening hours, flowers produced lesser amount of energy (32.25 and 31.80 joules, respectively). Perusal of the literature revealed no studies on these aspects in $T$. alexandrinum. These investigations thus, form the first report. However, Nagar and Chaudhary (2005) on strawberry and Chaudhary (2006) on peach reported similar observations of higher energy production by mature flowers and at the noon hours and the minimum in just opened ones. Similar strategy of bioenergetics in bee flowers was also reported by Heinrich (1975) and Abrol (1985; 1992). In conclusion, tThe maximum amount of dry nectar (DNS) was produced by fully opened flowers at all observation periods of 1000,1300 and $1600 \mathrm{~h}$ (2.468 $\mathrm{mg} /$ flower), while the minimum amount was produced by just opened flowers at $16.00 \mathrm{~h}(1.335 \mathrm{mg} /$ flower $)$.

\section{References}

Abrol, D.P. 1985. Analysis of biophysical interaction in causing foraging behavior of some bees- A study in bioenergetics. Ph.D. Thesis submitted to CCS Haryana Agricultural University, Hisar, India.

Abrol, D.P. 1992. Bioenergetics in bee flower interrelationship: an analysis of foraging behavior. Korean Journal of Apiculture, 7(1): 39-66.

Abrol, D.P. and Kapil, R.P. 1991. Foraging strategies of honeybees and solitary bees as determined by nectar sugar components. Proceedings of the Indian National Science Academy Part B, Biological Sciences, 57(2): 127-132.

Braun, E., MacVicar, R.M., Gibson, D.A., Pankiw, P. and Guppy, J. 1953. Studies in red clover seed production. Kansas Journal of Agriculture Science, 33: 437447.

Chaudhary, O. P. 2007. Management of Varroa destructor. IBA, Ludhiana, India, p. 90.

Chaudhary, O.P. 2006. Resource partitioning by different floral visitors on rape seed and mustard. Journal of Insect Science, 19(2): 171-177.

Heinrich, B. 1975. Energetics of pollination. Annual Review of Ecology Systematic, 6: 137-171.

Jablonski, B. (1974). Biology of flowering and pollination in red clover. Pszczelnicze Zeszyty Naukowe, 18: 229235.

Maurizio, A. and Pinter, L. 1961. Beobachtungen fiber die nektarabsonderung und den isektenbesuch bei einigen schweizerischen mattenklee hofsorten (Trifolium pratense L.). Arbeiten Futterba, pp. 41-46. 
McGregor, S.E. and Todd, F.E. 1952. Cantaloupe production with honeybees. Journal of Economic Entomology, 45: 43-47.

Nagar, P. and Chaudhary, O.P. 2005. Nectar secretion rhythms of strawberry (Fragaria xananassa) flowers. Korean Journal Apiculture, 20(1): 39-46.

Narayanan, E.S., Sharma, P.L., and Phadke, K.G. (1961). Studies on requirements of various crops for insect pollination insect pollinators of Egyptian clover (Triflolium alexandrinum) with particular reference to honey bees and their role in seed setting. Indian Bee Journal, 23(4/6): 23-30.

Pedersen, M.W. (1953). Seed production in alfalfa as related to nectar production and honeybee visitation. Botany Gazette, 115: 129-38.

Pedersen, M.W. and Bohart, G.E. (1953). Factors responsible for the attractiveness of various clones of alfalfa to pollen collecting bumble bees. Agronomy Journal, 45: 548-551.

Pedersen, M.W. and Todd, F.E. (1949). Selection and tripping in alfalfa clones by nectar-collecting honey bees. Agronomy Journal, 41: 247- 249.

Roberts, R.B. (1979). Spectrophotometric analysis of sugar produced by plants and harvested by insects. Journal of Apiculture Research, 18: 191-195.

\section{How to cite this article:}

Jat, M.K., O.P. Chaudhary and Tetarwal, A.S. 2018. Nectar Secretion Rhythms and Nectar Energetics of Trifolium alexandrinum Flowers. Int.J.Curr.Microbiol.App.Sci. 7(12): 559-566. doi: https://doi.org/10.20546/ijcmas.2018.712.070 